\title{
Biotransformation of Sinapic Acid Catalyzed by Momordica charantia Peroxidase
}

Hai-Li Liu, Xiang Wan, Xue-Feng Huang, Ling-Yi Kong*

Department of Natural Medicinal Chemistry, China Pharmaceutical University, 24 Tong Jia Xiang, Nanjing 210009, The People's Republic of China

* To whom correspondence should be addressed. Tel: +86 25 85391289. Fax: +86 25

85301528. E-mail: lykong@jlonline.com 


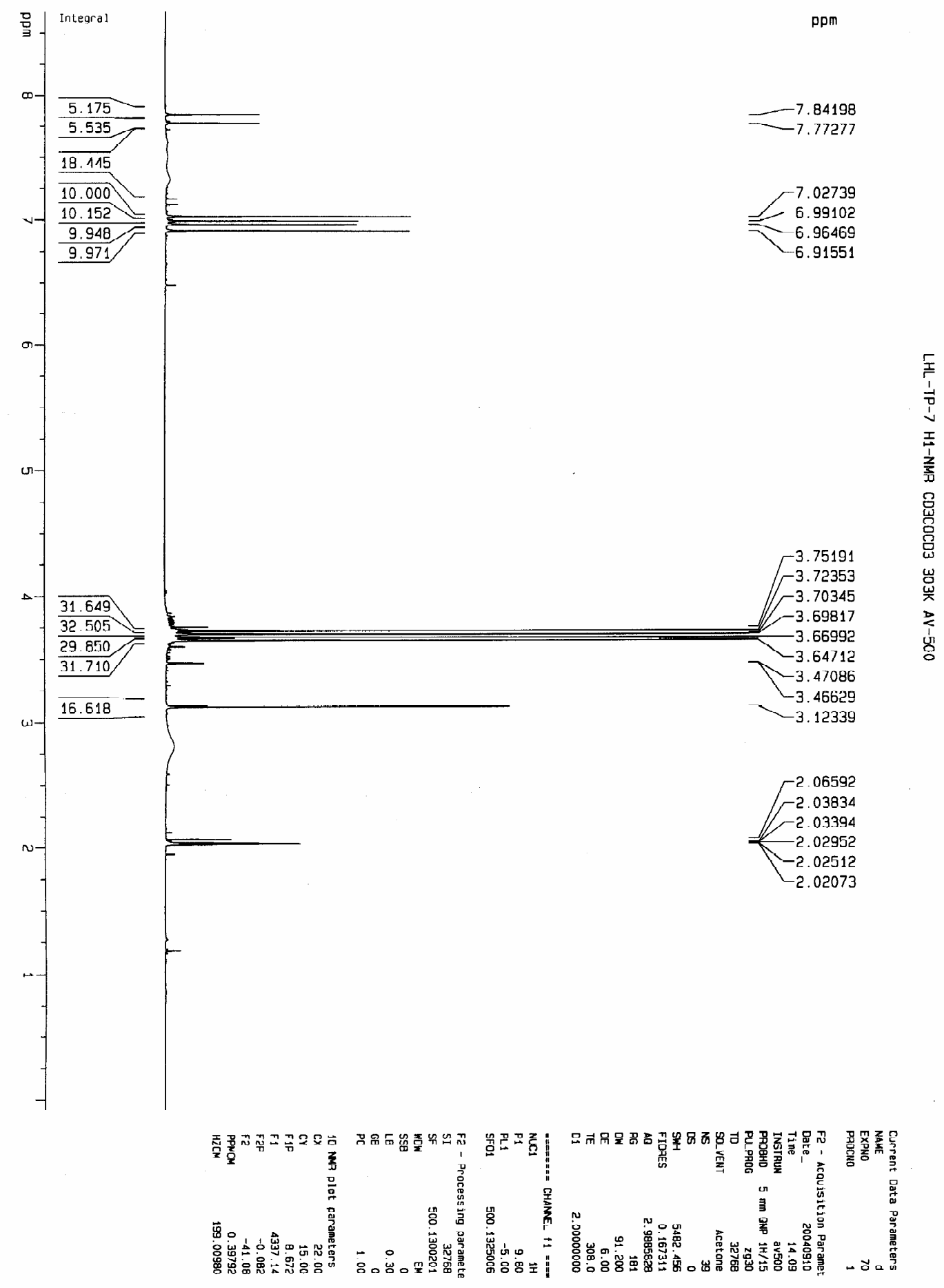

Figure $1{ }^{1} \mathrm{H}$ NMR spectrum of tetraSA1 (2) (acetone- $d_{6}, 500 \mathrm{MHz}$ ) 


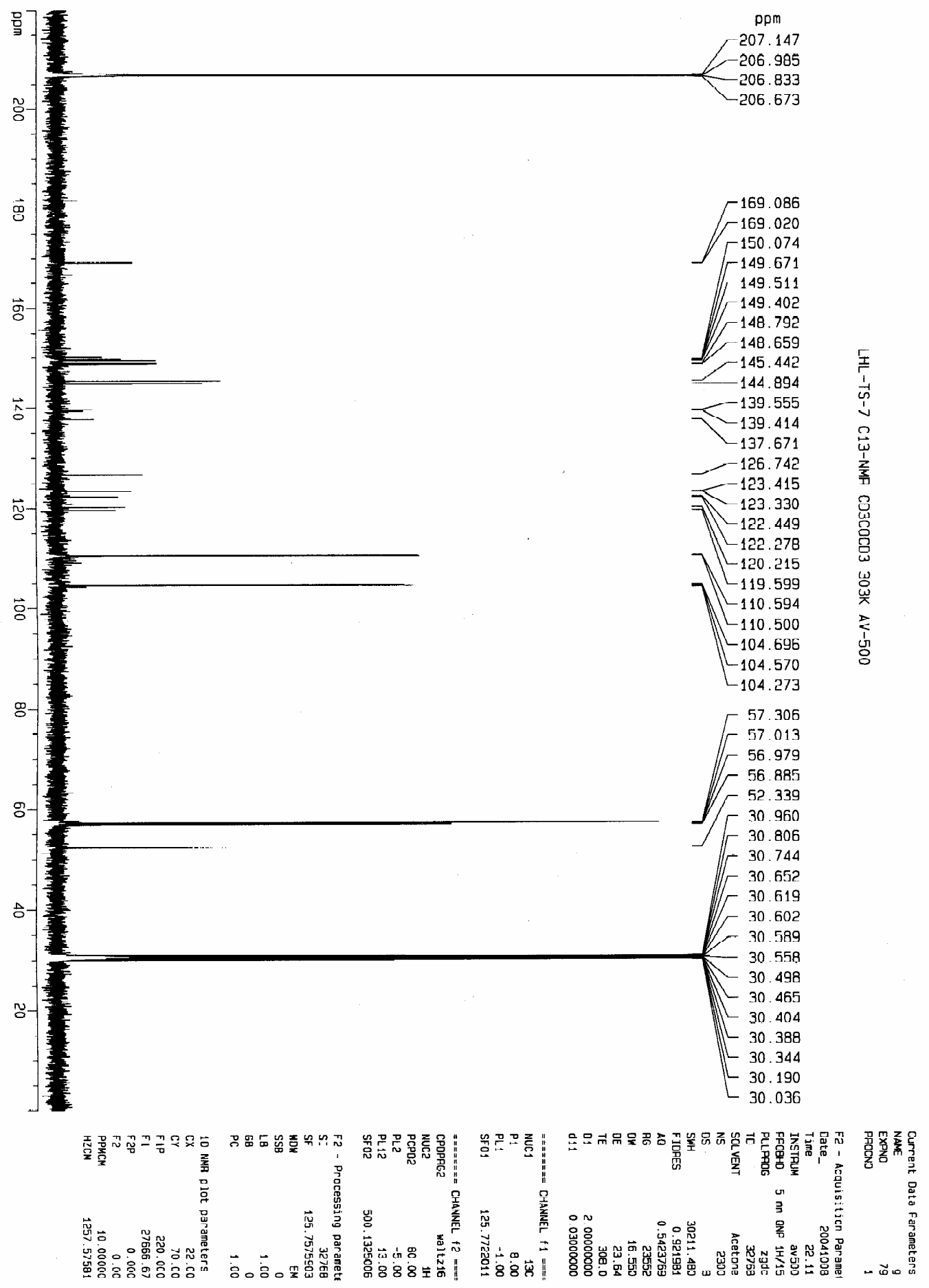

Figure $2{ }^{13} \mathrm{C}$ NMR spectrum of tetraSA1 (2) (acetone- $d_{6}, 125 \mathrm{MHz}$ ) 


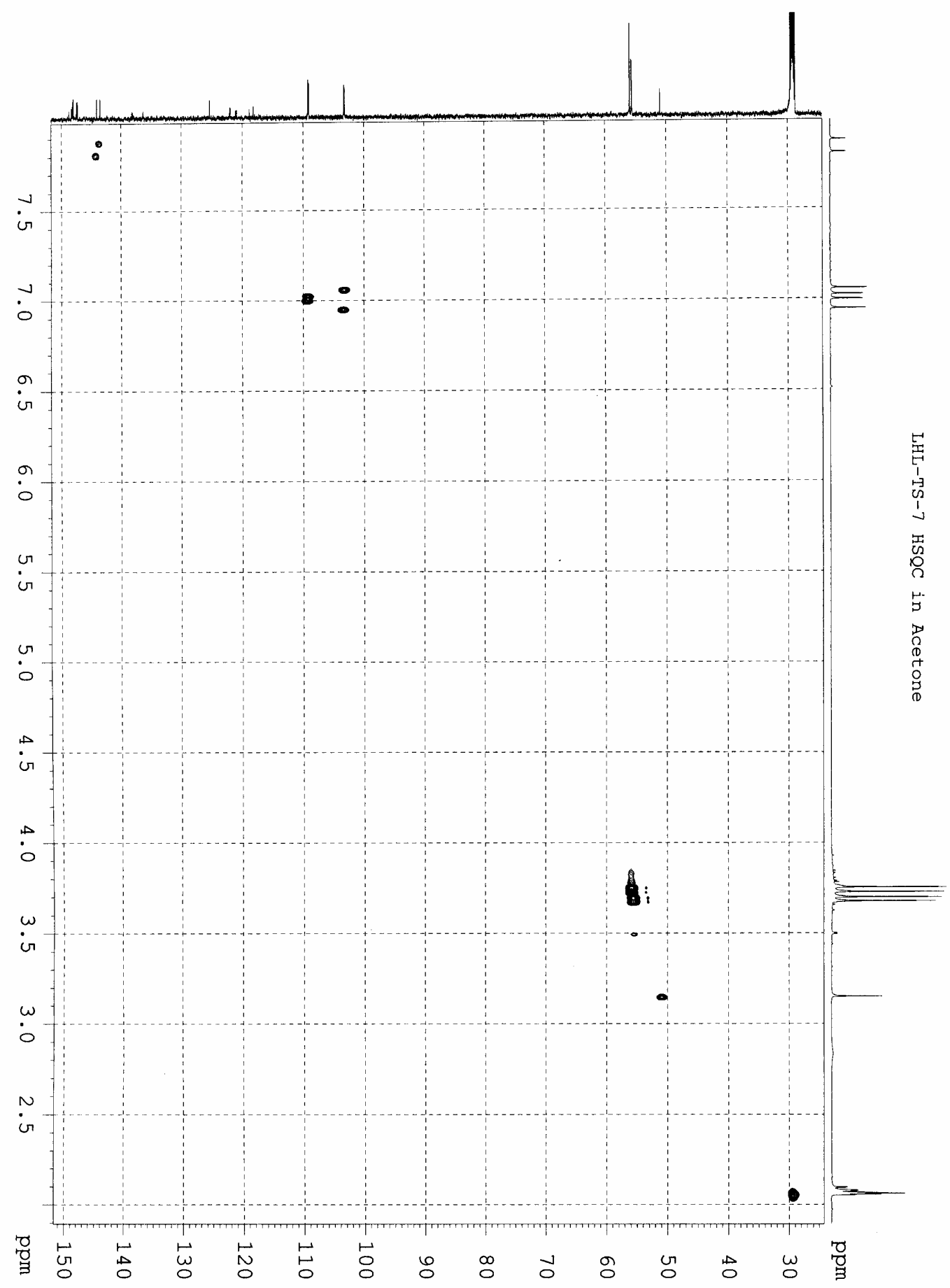

Figure 3 HSQC spectrum of tetraSA1 (2) (acetone- $\left.d_{6}, 600 \mathrm{MHz}\right)$ 


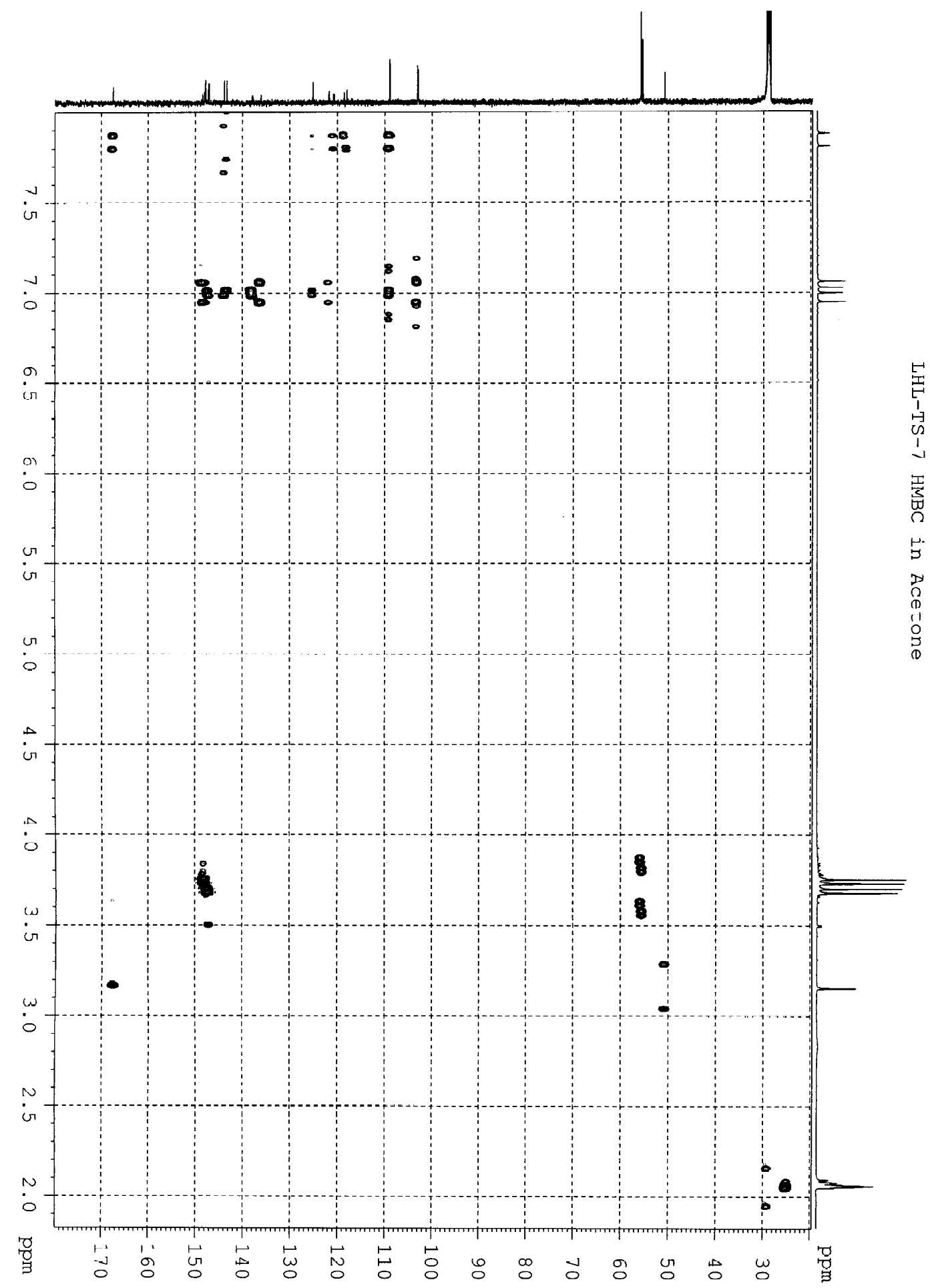

Figure $4 \mathrm{HMBC}$ spectrum of tetraSA1 (2) (acetone- $d_{6}, 600 \mathrm{MHz}$ ) 


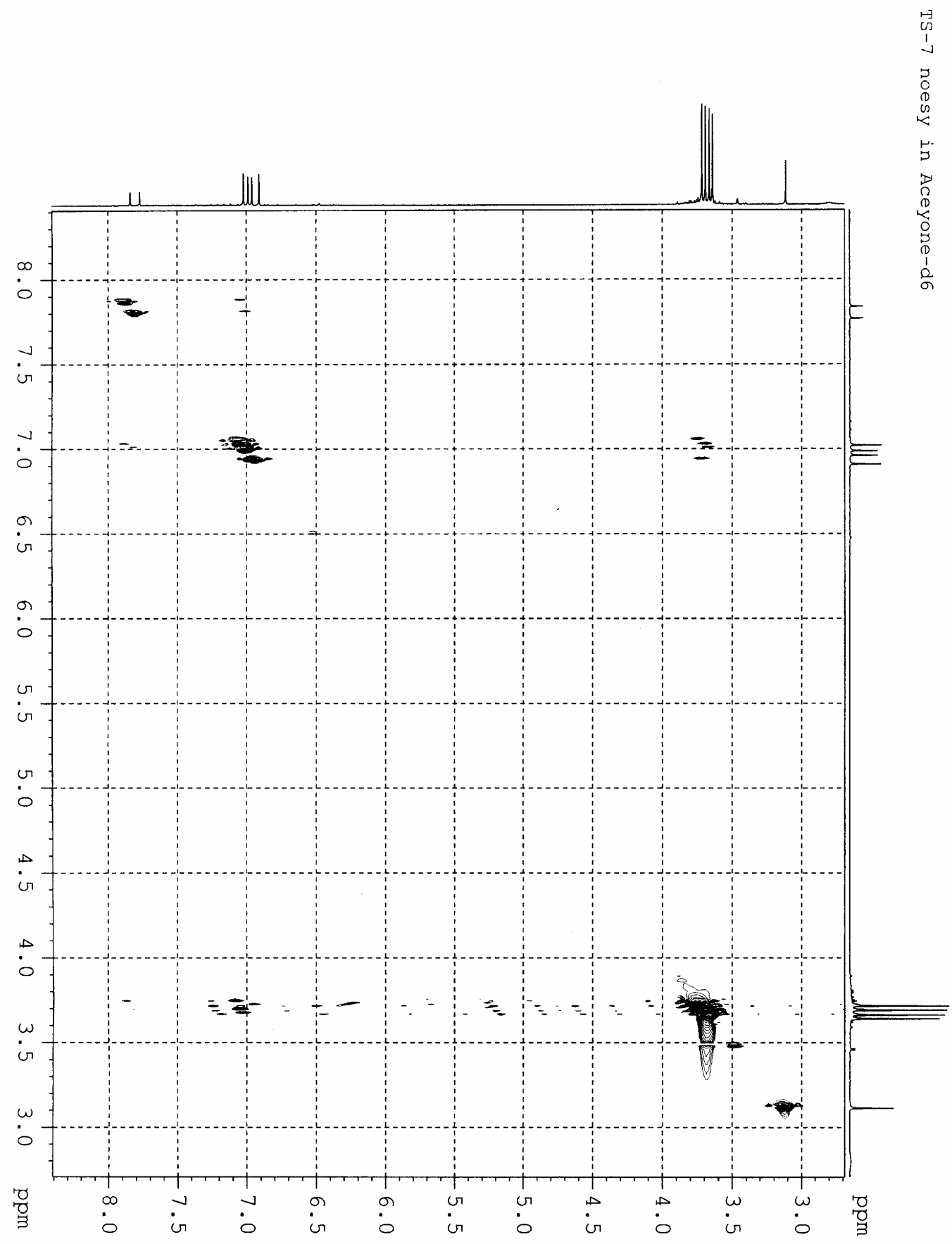

Figure 5 NOESY spectrum of tetraSA1 (2) (acetone- $\left.d_{6}, 600 \mathrm{MHz}\right)$ 


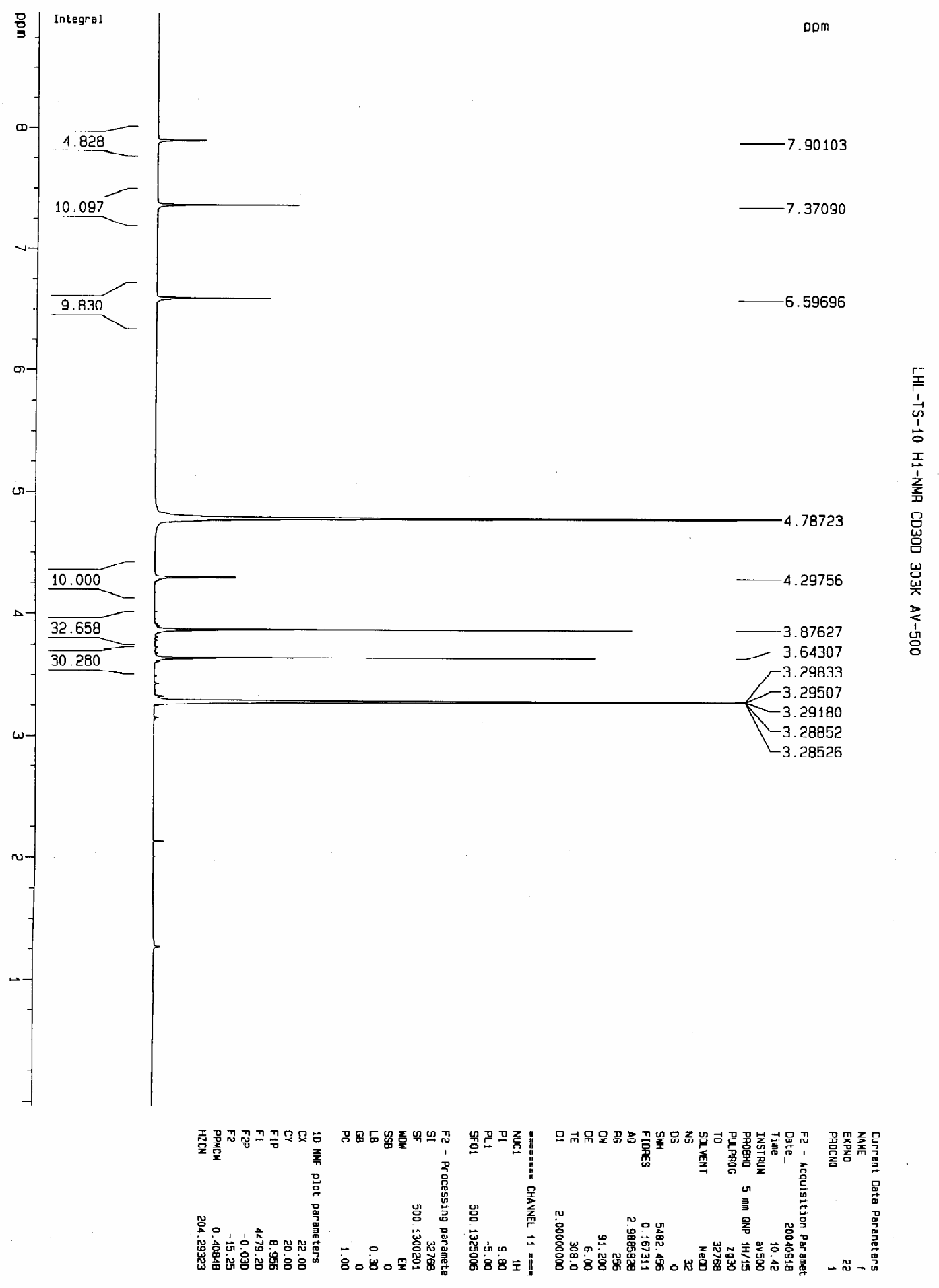

Figure $6{ }^{1} \mathrm{H}$ NMR spectrum of diSA1 (3) $\left(\mathrm{CD}_{3} \mathrm{OD}, 500 \mathrm{MHz}\right)$ 


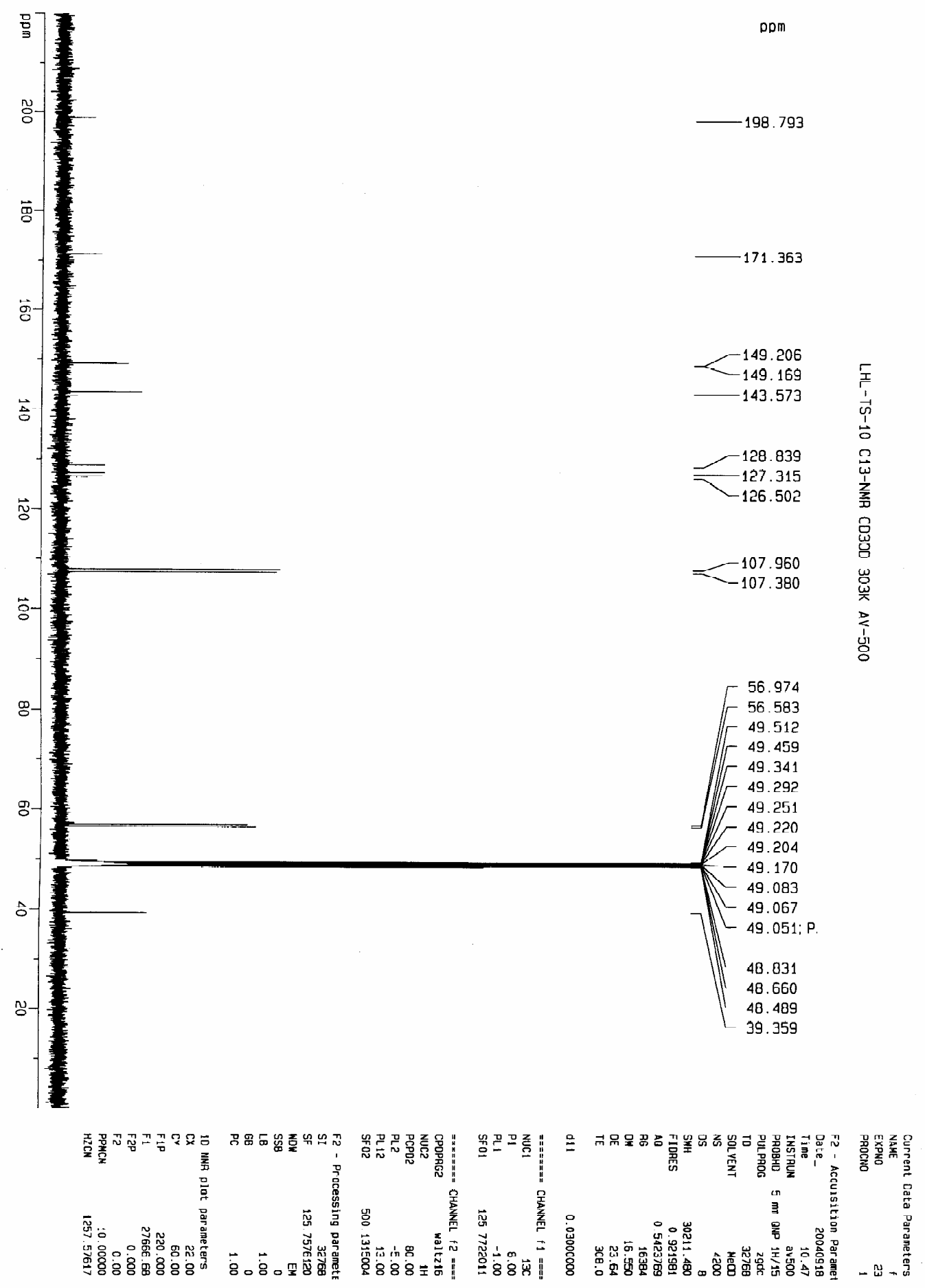

Figure $7{ }^{13} \mathrm{C}$ NMR spectrum of diSA1 (3) $\left(\mathrm{CD}_{3} \mathrm{OD}, 125 \mathrm{MHz}\right)$ 


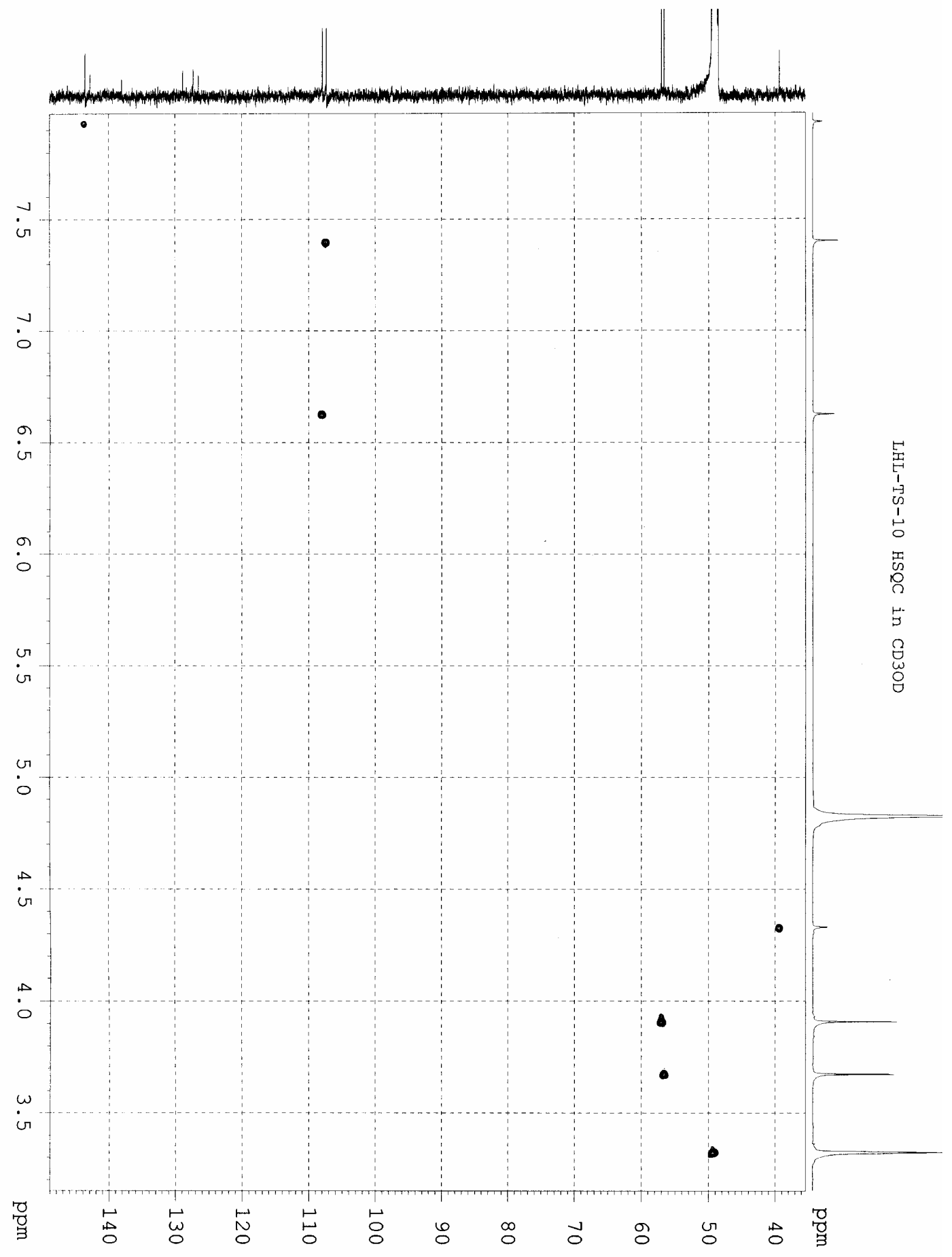

Figure $8 \mathrm{HSQC}$ spectrum of diSA1 (3) $\left(\mathrm{CD}_{3} \mathrm{OD}, 600 \mathrm{MHz}\right)$ 


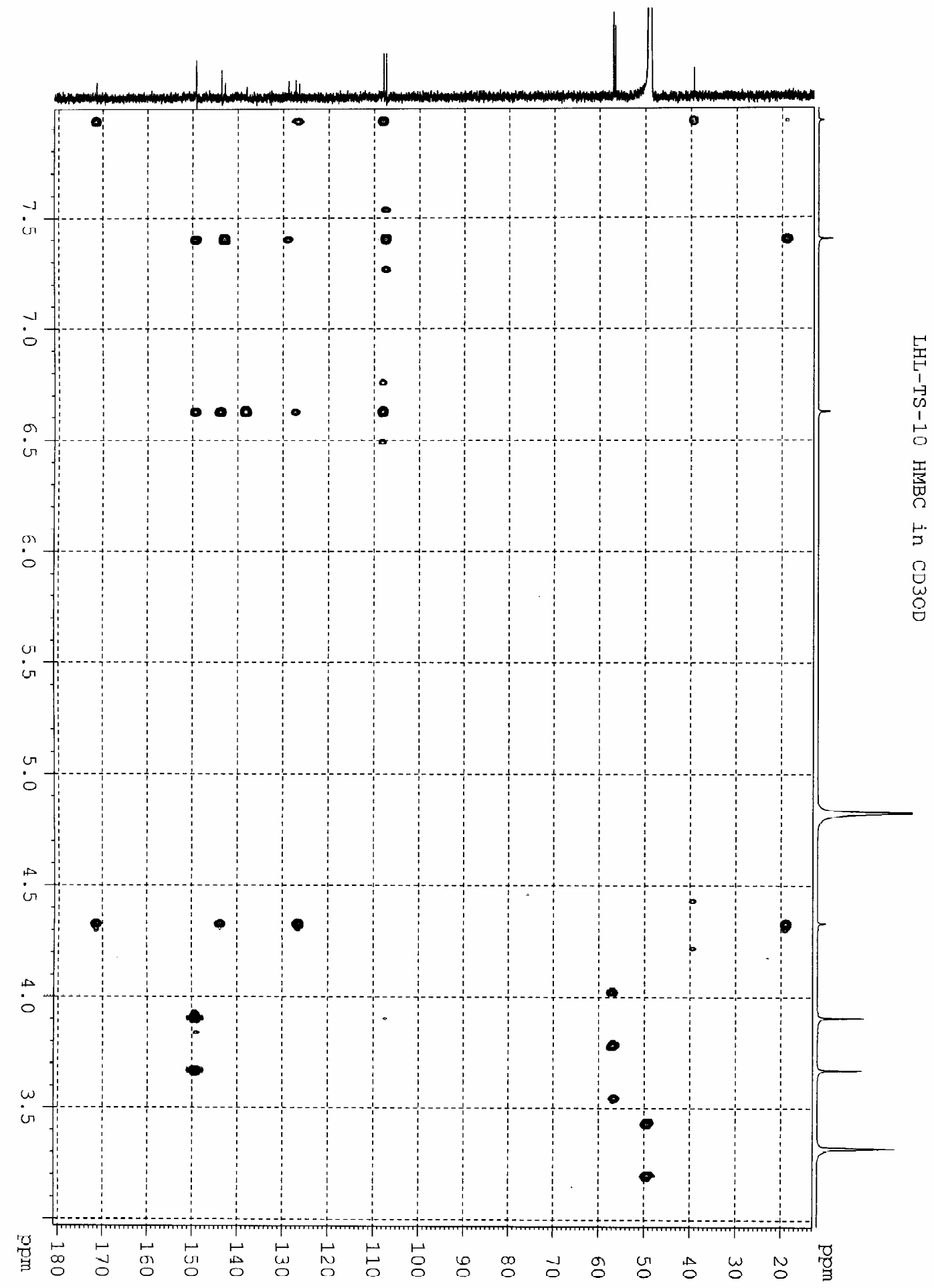

Figure $9 \mathrm{HMBC}$ spectrum of diSA1 $(3)\left(\mathrm{CD}_{3} \mathrm{OD}, 600 \mathrm{MHz}\right)$ 


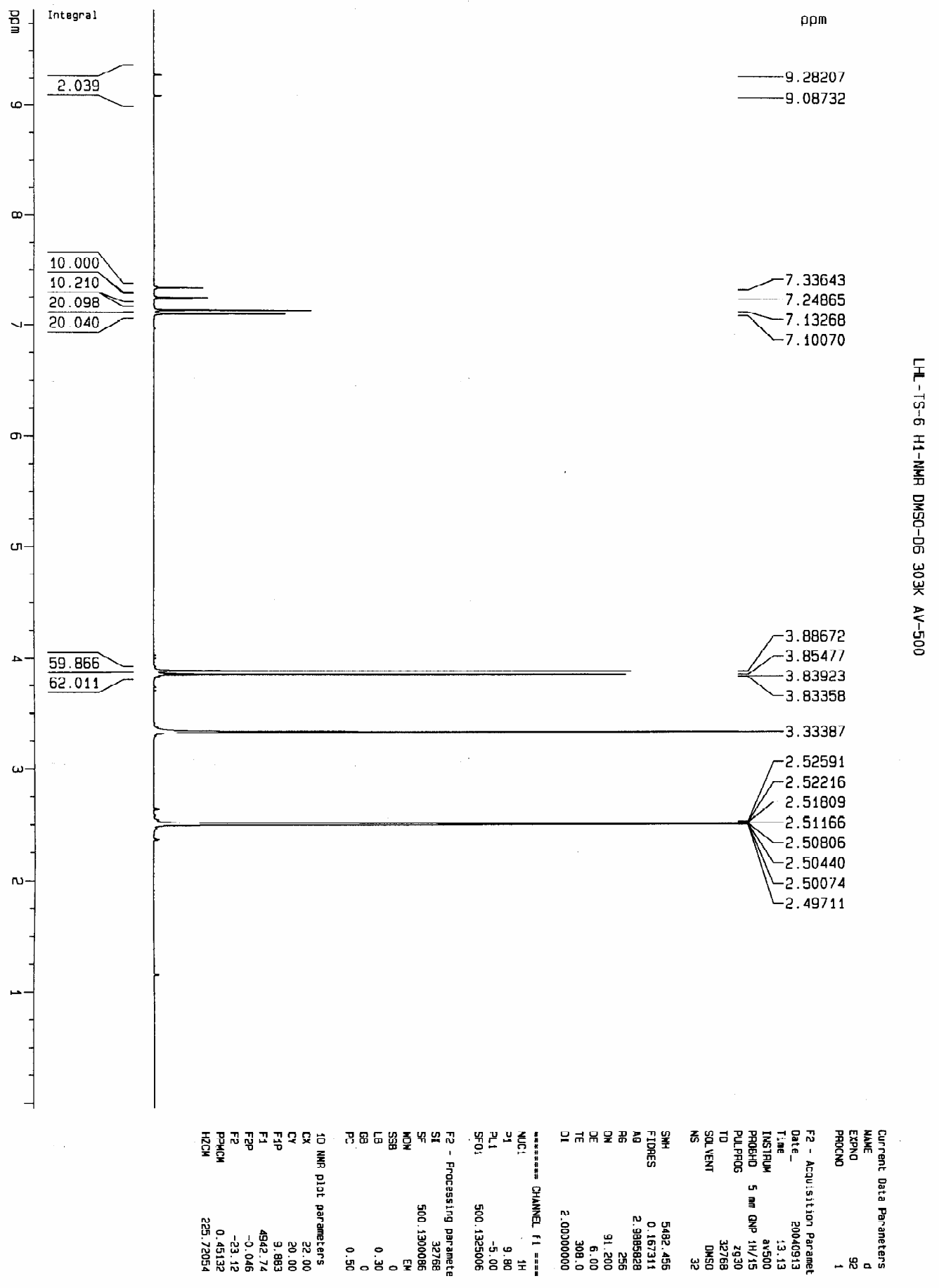

Figure. $10{ }^{1} \mathrm{H}$ NMR spectrum of diSA2 (4) (DMSO- $\left.d_{6}, 500 \mathrm{MHz}\right)$ 


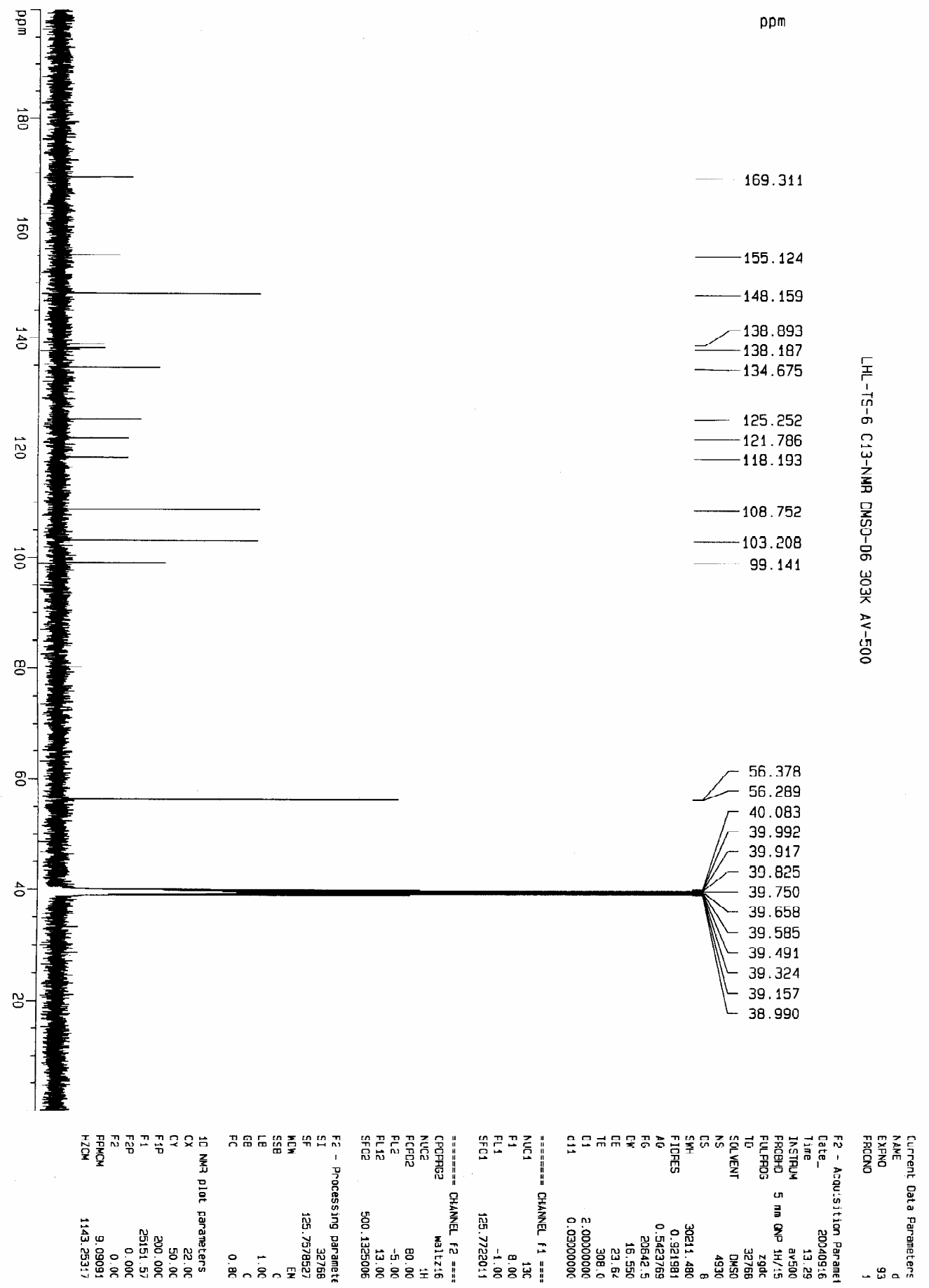

Figure $11{ }^{13} \mathrm{C}$ NMR spectrum of diSA2 (4) (DMSO- $\left.d_{6}, 125 \mathrm{MHz}\right)$ 


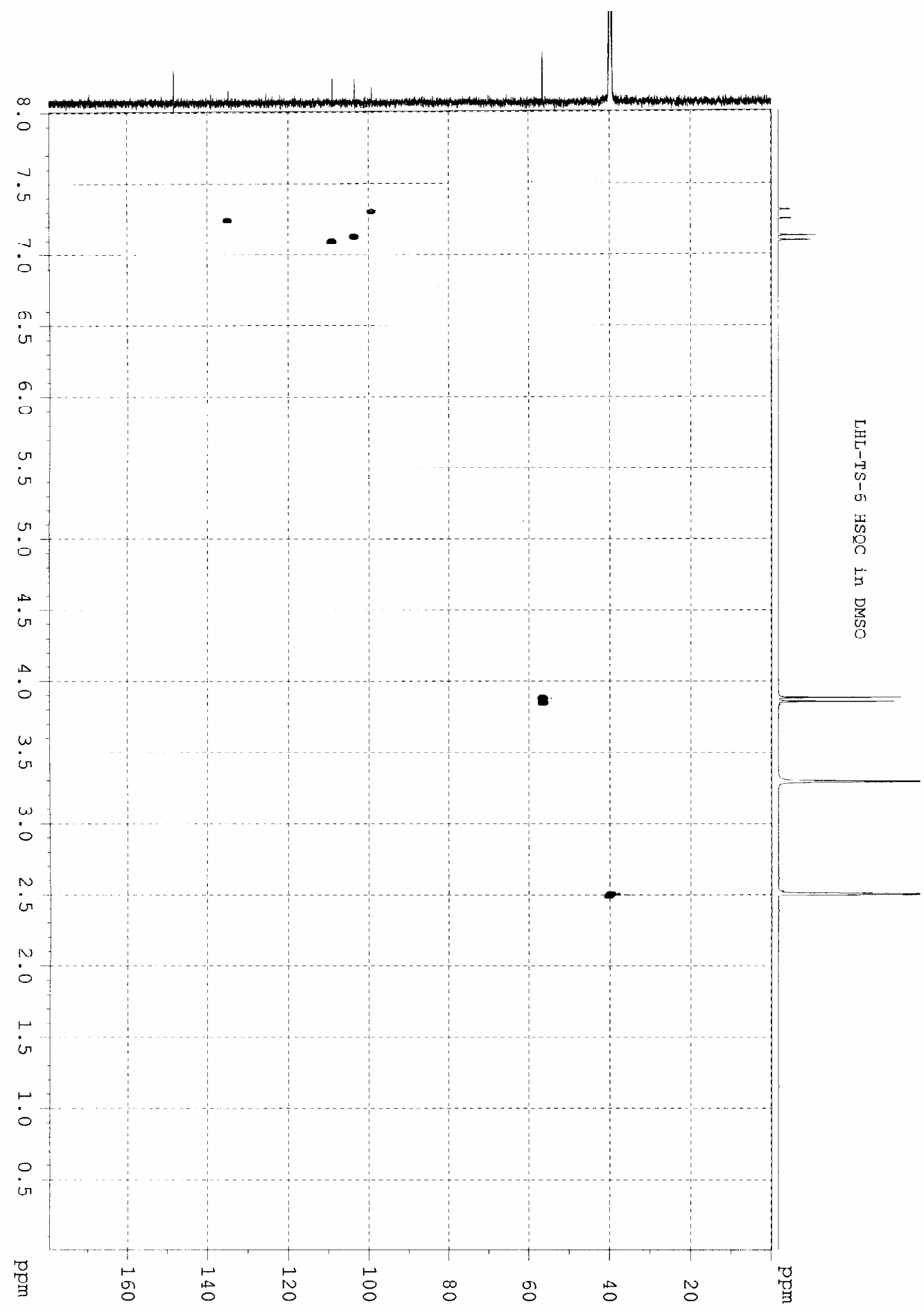

Figure 12 HSQC spectrum of diSA2 (4) (DMSO- $\left.d_{6}, 600 \mathrm{MHz}\right)$ 


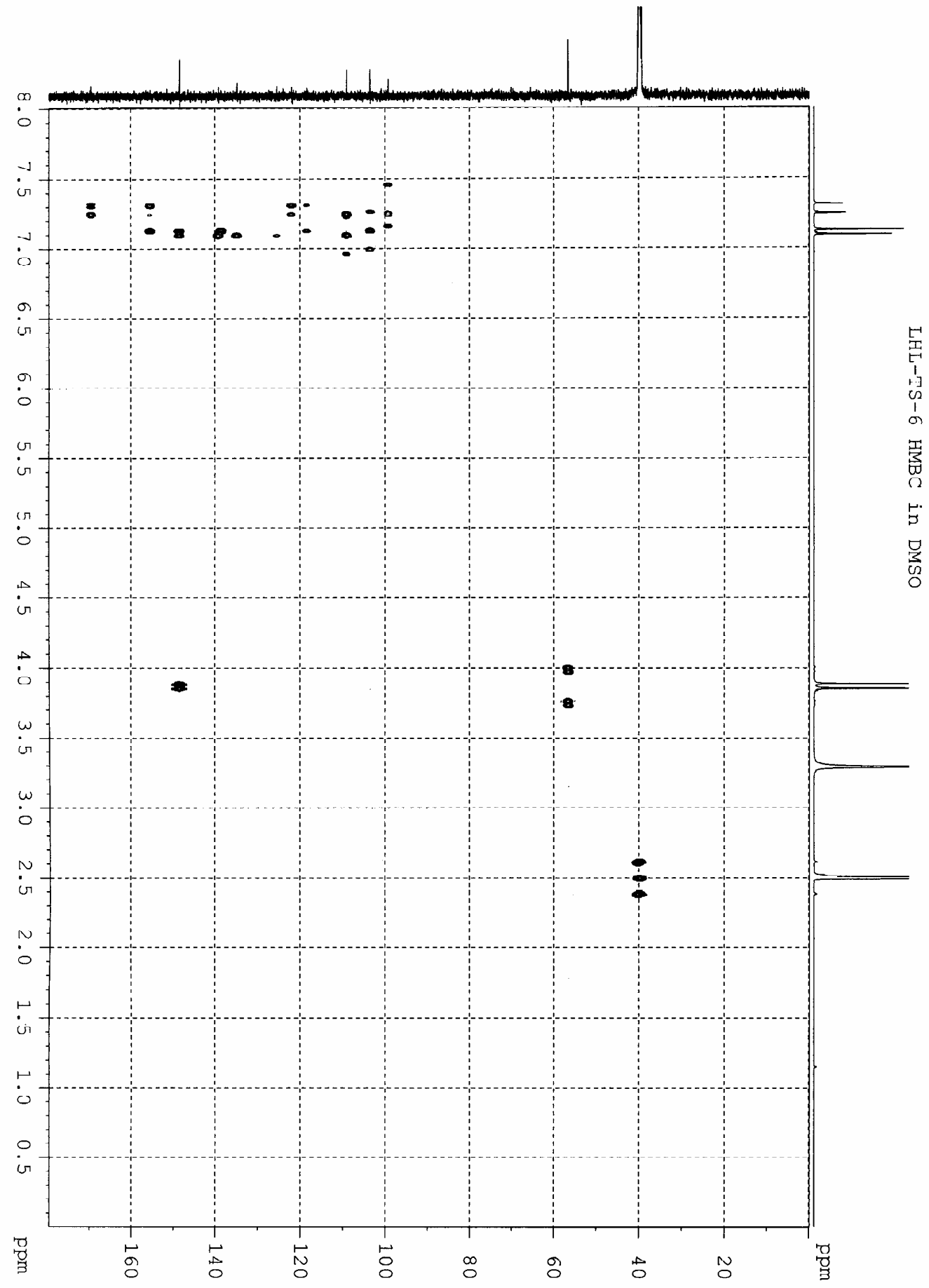

Figure 13 HMBC spectrum of diSA2 (4) $\left(\right.$ DMSO- $\left.d_{6}, 600 \mathrm{MHz}\right)$ 


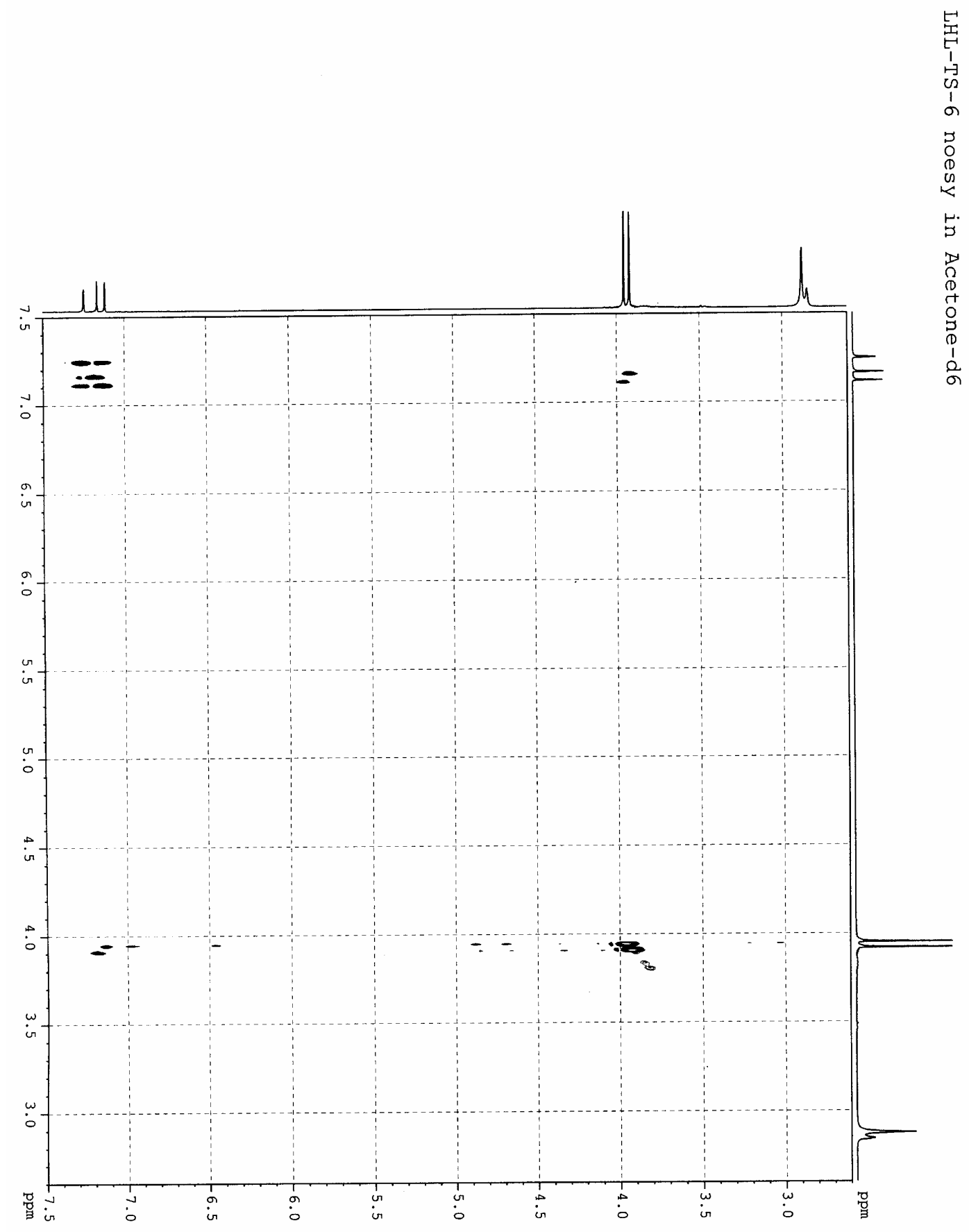

Figure 14 NOESY spectrum of diSA2 (4) (acetone- $\left.d_{6}, 600 \mathrm{MHz}\right)$ 


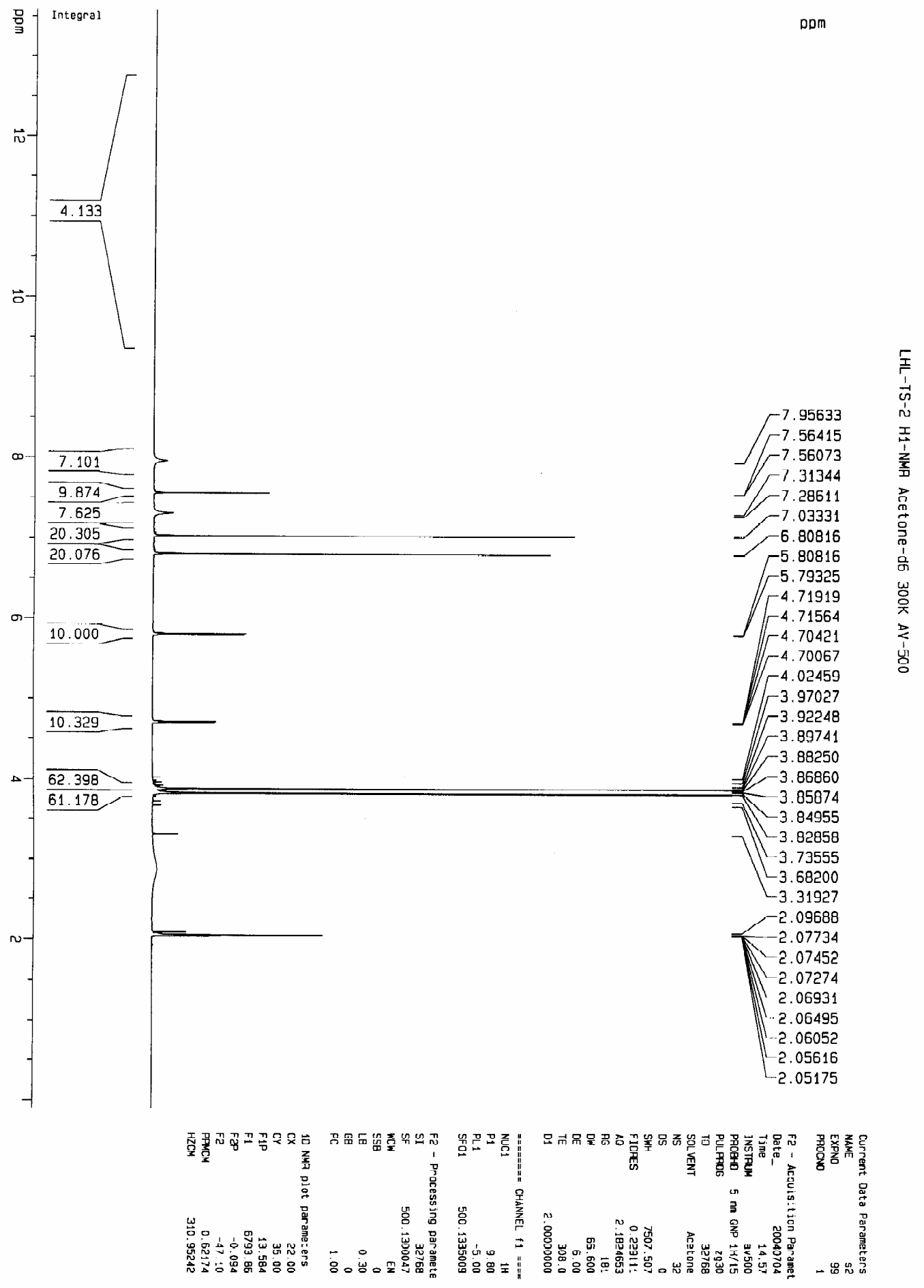

Figure $15{ }^{1} \mathrm{H}$ NMR spectrum of diSA3 (5) (acetone- $\left.d_{6}, 500 \mathrm{MHz}\right)$ 


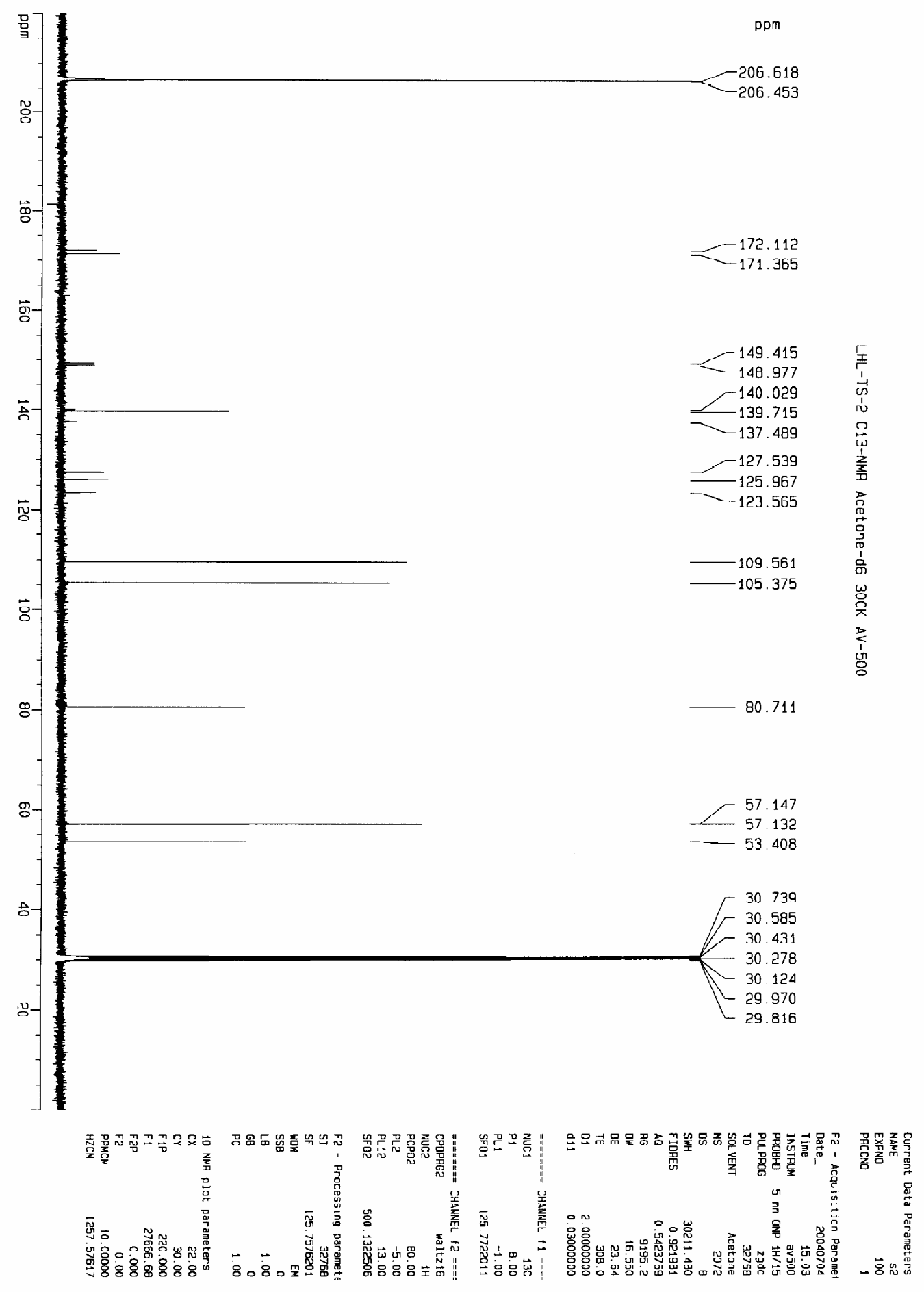

Figure $16{ }^{13} \mathrm{C}$ NMR spectrum of diSA3 (5) (acetone- $d_{6}, 125 \mathrm{MHz}$ ) 


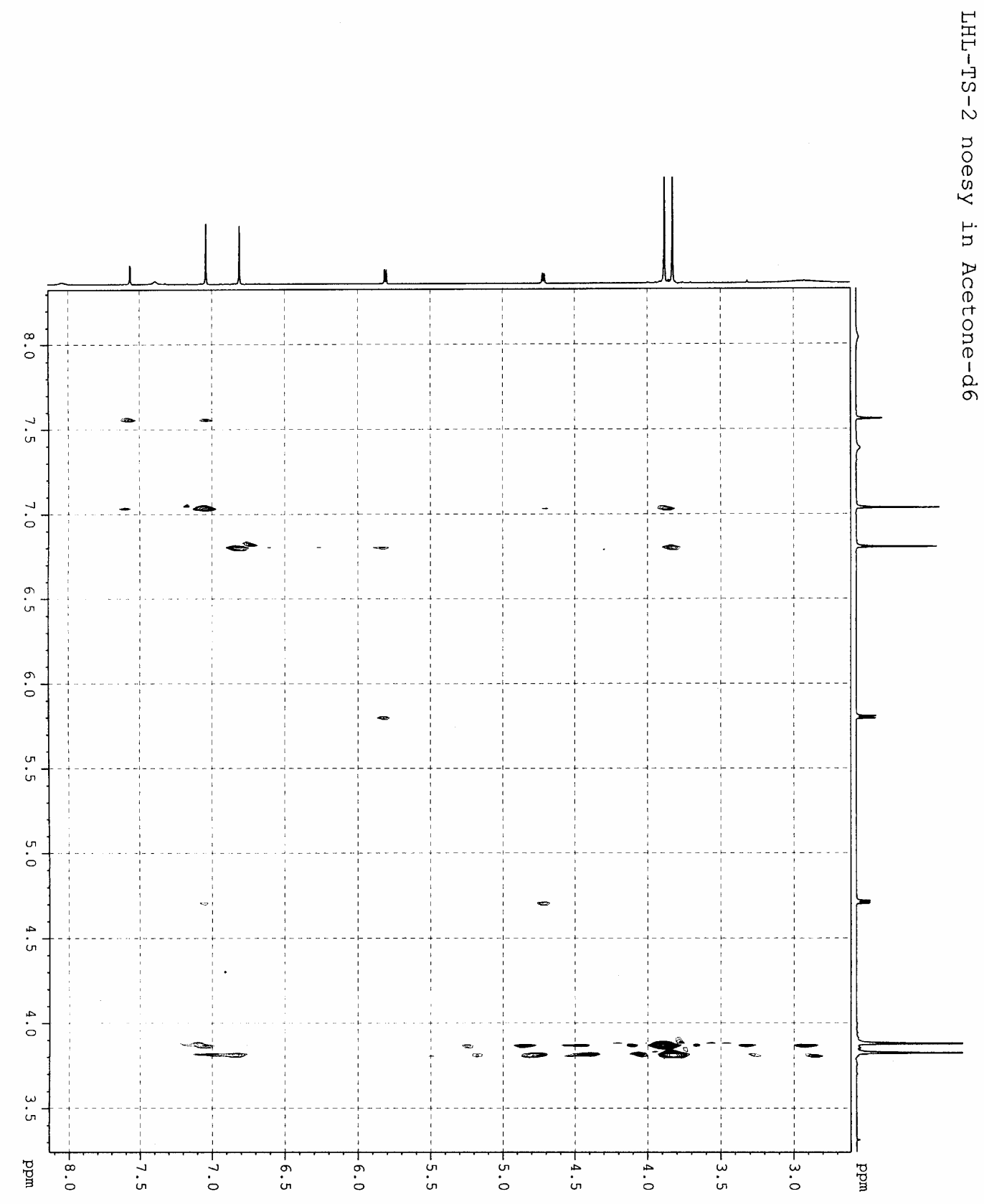

Figure 17 NOESY spectrum of diSA3 (5) (acetone- $d_{6}, 600 \mathrm{MHz}$ ) 


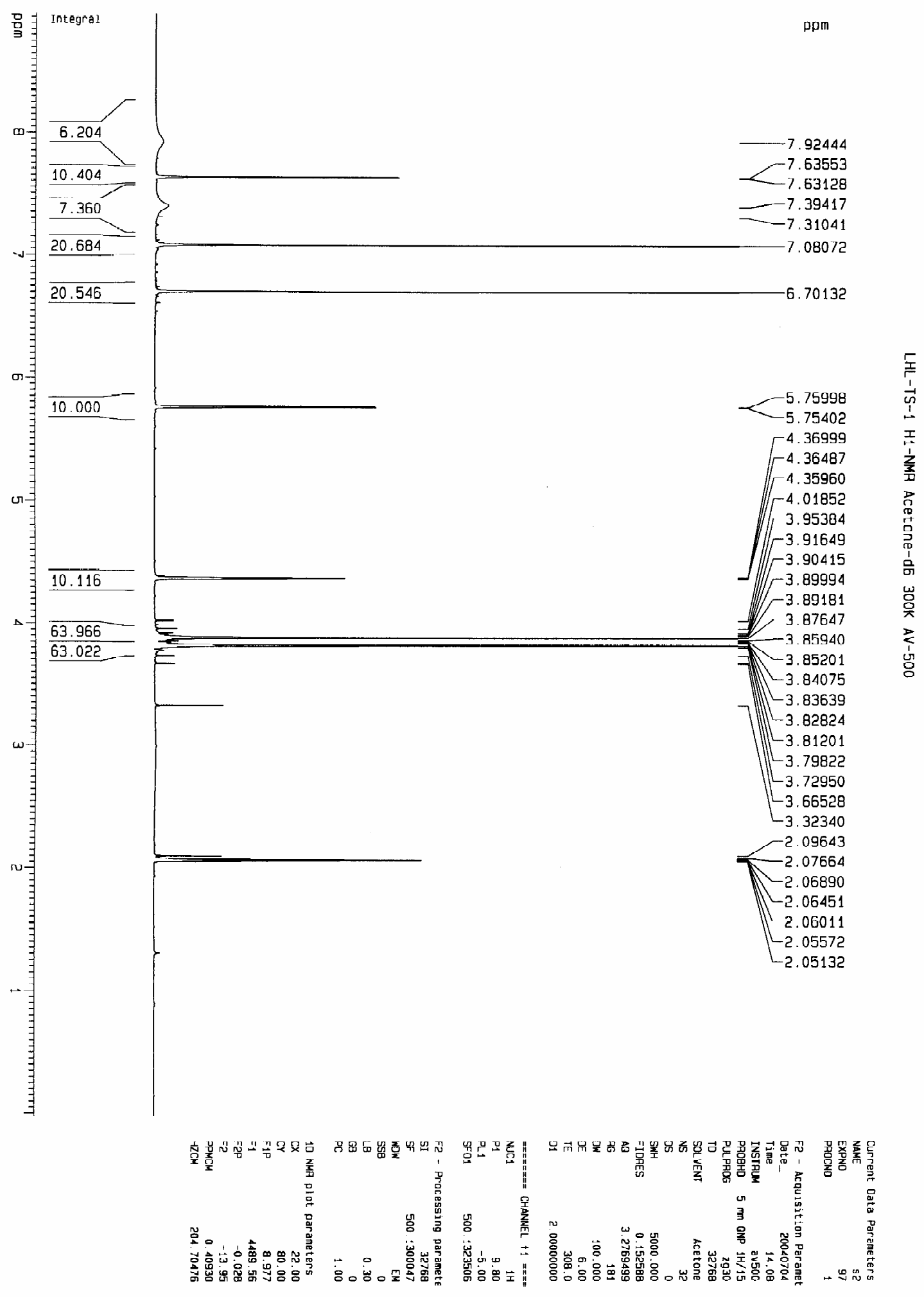


Figure $18{ }^{1} \mathrm{H}$ NMR spectrum of diSA4 (6) (acetone- $d_{6}, 500 \mathrm{MHz}$ )

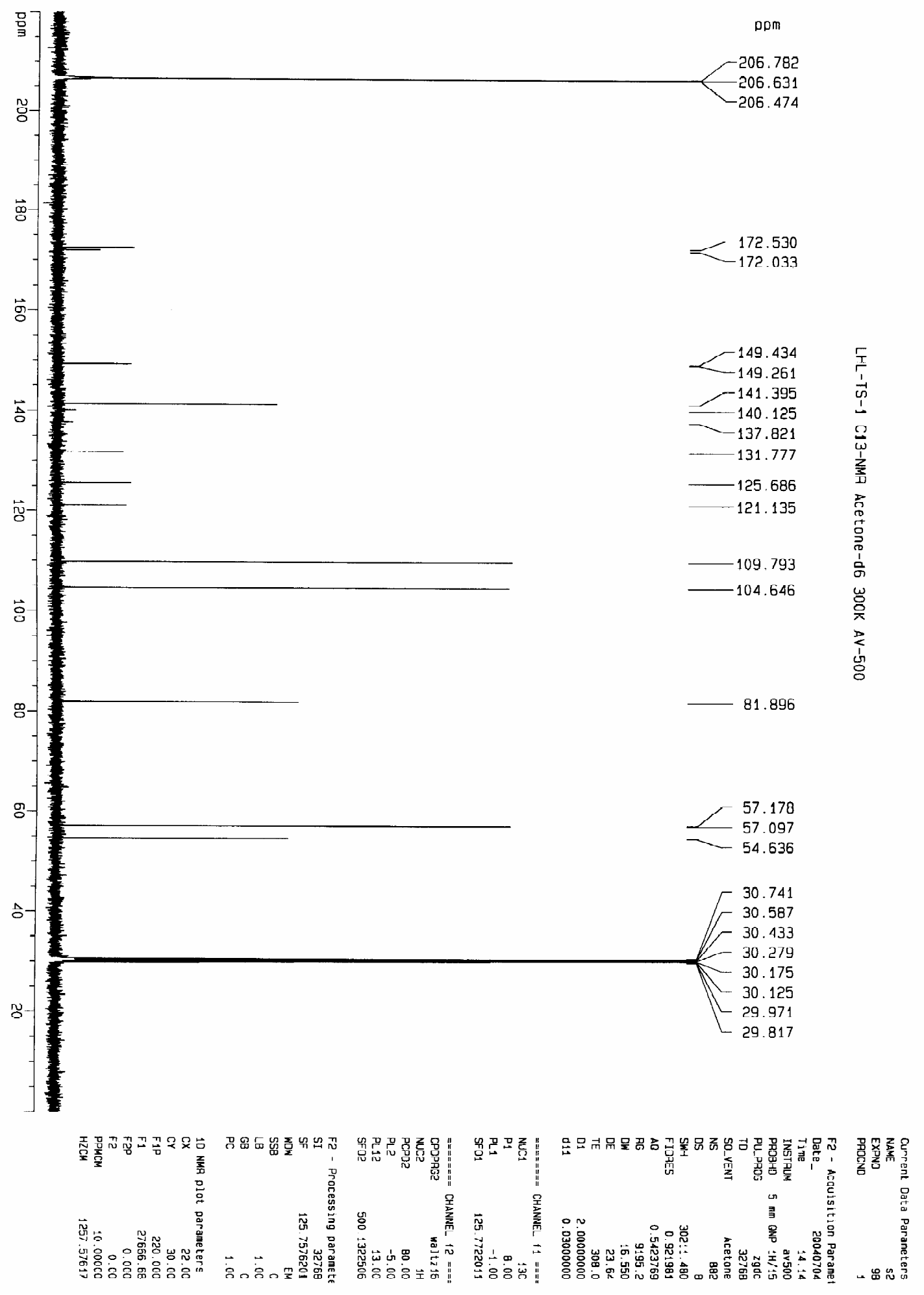


Figure $19{ }^{13} \mathrm{C}$ NMR spectrum of diSA4 (6) (acetone- $d_{6}, 125 \mathrm{MHz}$ )

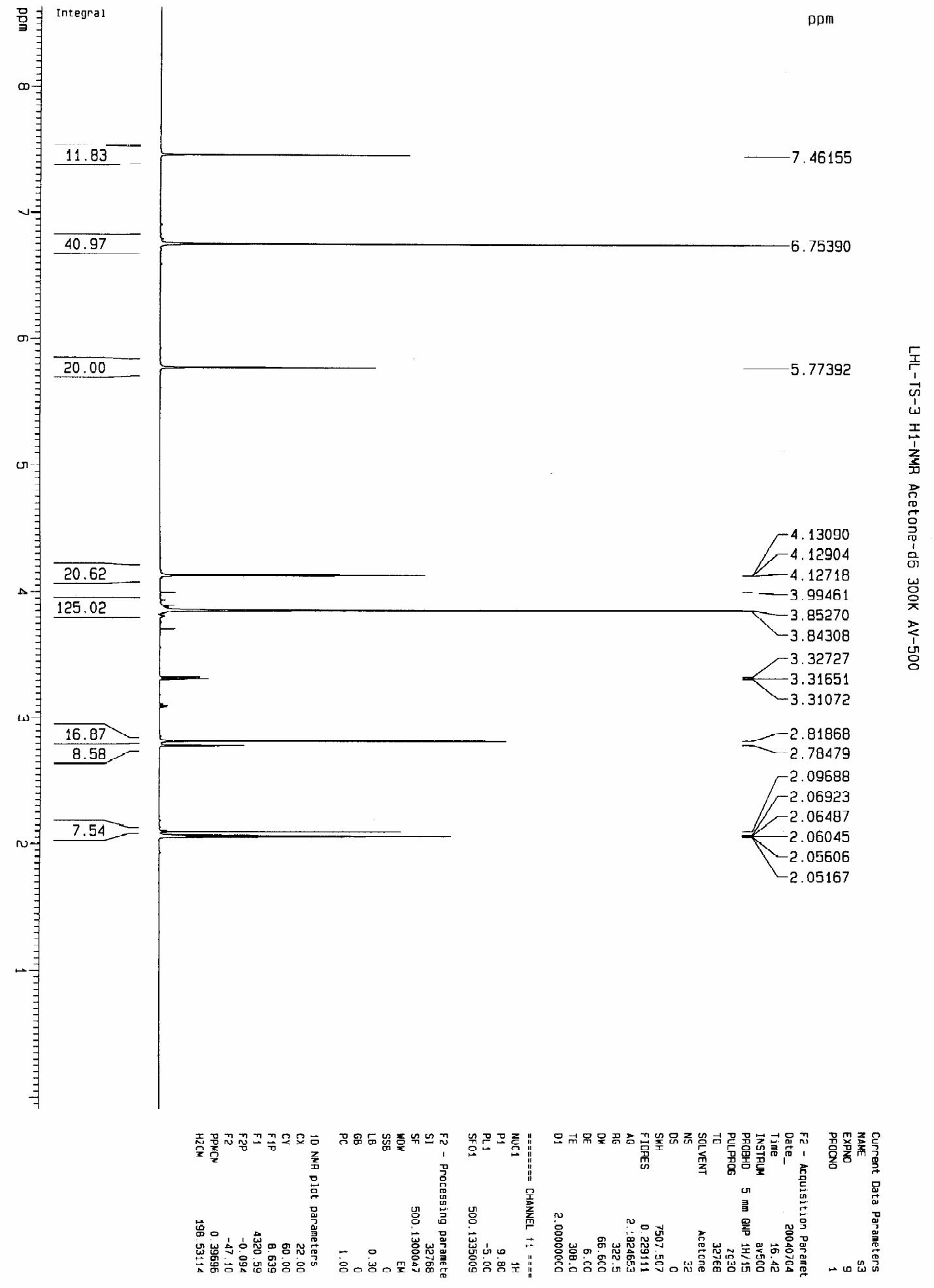


Figure $20{ }^{1} \mathrm{H}$ NMR spectrum of diSA5 (7) (acetone- $d_{6}, 500 \mathrm{MHz}$ )

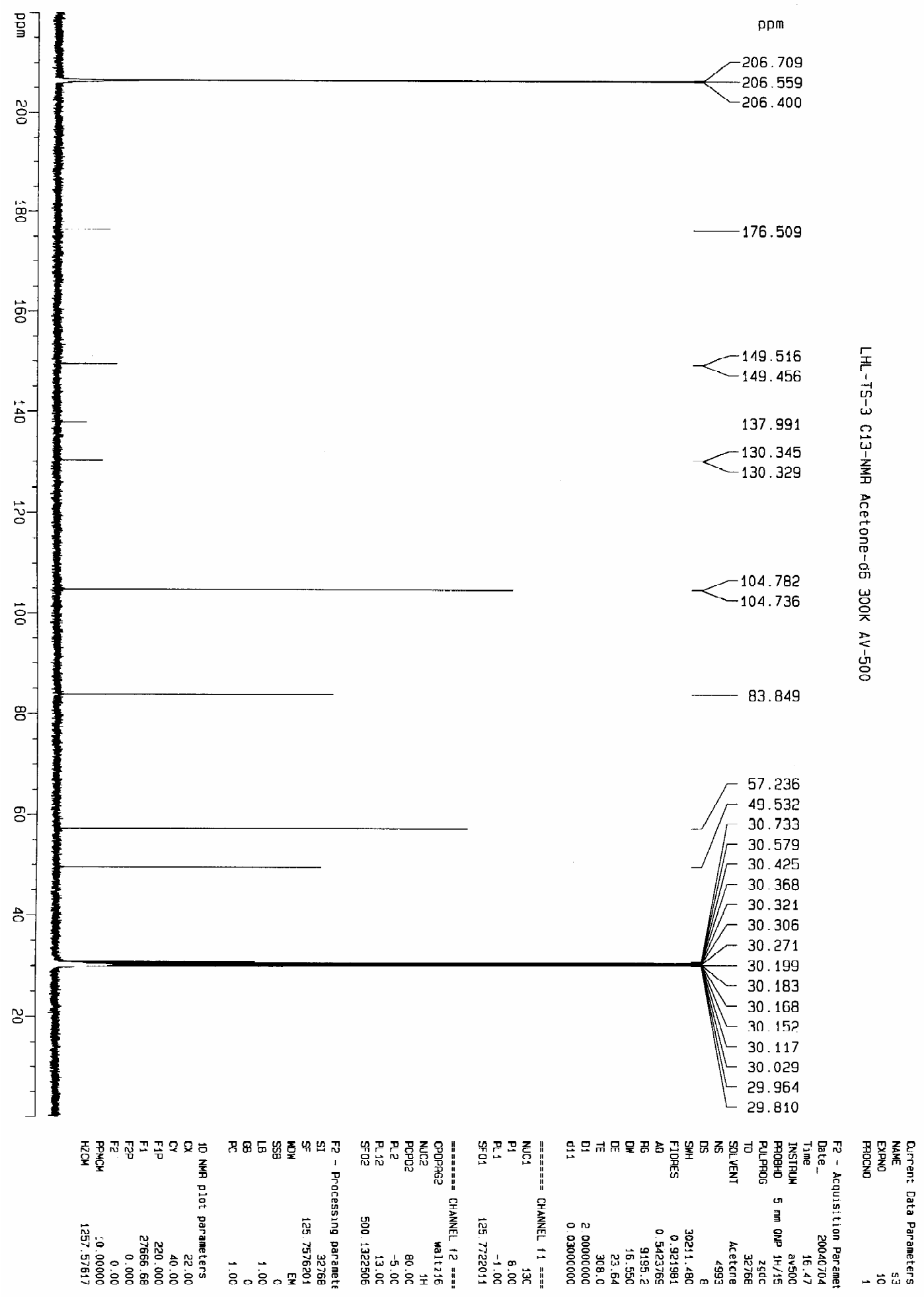


Figure $21{ }^{13} \mathrm{C}$ NMR spectrum of diSA5 (7) (acetone- $d_{6}, 125 \mathrm{MHz}$ ) 